Skinner Timothy (Orcid ID: 0000-0002-0018-6963)

\title{
The clinician factor: personality characteristics of clinicians and their impact upon clinical outcomes in the management of children and adolescents with type 1
} diabetes.

Cameron $\mathrm{FJ}^{1,2,3}$, Russell $\mathrm{E}^{3}$, McCombe $\mathrm{J}^{1}$, O’Connell $\mathrm{M}^{1,2,3}$, Skinner $\mathrm{T}^{4}$

Murdoch Children's Research Institute, Melbourne, Australia ${ }^{1}$

Department of Paediatrics, University of Melbourne ${ }^{2}$

Royal Children's Hospital, Melbourne ${ }^{3}$

Psychological and Clinical Sciences School, Charles Darwin University, Darwin, Australia ${ }^{4}$

This is the author manuscript accepted for publication and has undergone full peer review but has not been through the copyediting, typesetting, pagination and proofreading process, which may lead to differences between this version and the Version of Record. Please cite this article as doi: $10.1111 /$ pedi.12646

This article is protected by copyright. All rights reserved. 


\begin{abstract}
Objective- The purpose of this study was to estimate clinician qualities that influence metabolic outcomes in youth with type 1 diabetes.

Research Design and Methods- Data was gathered over two 3 month periods in a large tertiary diabetes centre (1500 patients, 8 clinicians) from patients with type 1 diabetes who received continuous care from each clinician. Data included sex, age, diabetes duration, insulin regimen, body mass index, insulin dose and episodes of severe hypoglycaemia. Clinician data included target blood glucose levels, target HbA1C, Diabetes Attitude Scale and Big 5 Personality Inventory Scale. Mean HbA1C per clinician was the primary outcome variable.
\end{abstract}

Results- The 8 clinicians saw a total of 464 patients during the first time period, and 603 in the second time period. Lowest to highest mean $\mathrm{HbA} 1 \mathrm{C}$ per clinician varied by $0.7 \%$. There were small but statistically significant differences between clinicians with their patients' age at diagnosis, duration of diabetes, age, gender, treatment type and BMI SD score. After controlling for these differences, the clinician characteristics that were associated with lower mean HbA1C were having no lower limit in target $\mathrm{HbA} 1 \mathrm{C}$ and being self-reportedly 'less agreeable'. The impact of these clinician attitudinal traits were equivalent to the combined effects of patient characteristics and treatment type.

Conclusions- There was a significant variation in metabolic outcomes between treating clinicians. After controlling for patient clinical differences, clinician mean $\mathrm{HbA1C}$ was associated with lower limit in target $\mathrm{HbA} 1 \mathrm{C}$ and being 'less agreeable'. Clinicians who were more demanding and dogmatic appeared to have better outcomes. 
At its core, the management of a child or adolescent with type 1 diabetes (T1DM) is an exercise in applied behavioural paediatrics. Clinicians are encouraging their patients and families to repetitively engage in behaviours that are perceived as alien, painful and restrictive. The origins of the disease are enigmatic, embedded in societal confusion and frequently associated with degrees of misplaced parental guilt. The goals of therapy are to avoid acute and chronic complications which for the patient and their family are simultaneously both threatening and abstract. The existential burden of type 1 diabetes of T1DM in childhood has been long-recognised to be significant (1) and not surprisingly often associated with family conflict, mental health issues in both child and care-givers and disrupted family life. Thus the paediatric diabetologist needs to be skilled in medical, emotional and behavioural aspects of care.

The importance and impact of the individual therapists' characteristics and therapeutic alliance between patients and clinician have been well documented in the behavioural and mental health literature (2). The charismatic qualities and personality type of the therapist frequently influence clinical outcomes. These characteristics may be as seemingly banal as the likeability and empathic skills of the therapist to more complex issues such as therapist heuristics (or personal mindlines that determine how people make decisions) and cognitive biases (3). Acknowledgement of the importance of these characteristics recognizes that clinical interactions are not uni-directional. Notions of transference and countertransference or the exchange of emotion reactions between patient and clinician are also well 
recognized. The importance though of therapist variability in adolescent mental health care has recently been challenged (4).

In practical terms most diabetes teams can easily identify those clinicians who are 'good' at talking to 'difficult' patients. Setting aside the ascribed values of 'good' and 'difficult', this visceral recognition reflects the potential importance of an individual clinician in influencing patient outcome. Notwithstanding this tacit clinical reality, there has been little attention paid to the impact of clinician type in the paediatric diabetes literature. Reviews of psychosocial interventions have referred to the importance of individual therapists (5) and frequent non-transferability of their skills. Multi-centre outcome studies have also occasionally identified idiosyncratic clinician qualities that have had a seemingly disproportionately positive impact on outcomes but are again difficult to transfer (6). The purpose of this study is to investigate these qualities in a systematic manner. In an attempt to isolate clinician qualities from all of the other aspects of care, we have exploited the context of several clinicians operating side by side providing continuous care for randomly allocated patients, within the same tertiary care setting with homogenous allied health team support.

\section{Methods}

Clinical care setting 
This study was conducted within the diabetes clinic at the Royal Children's Hospital (RCH), Melbourne. This clinic cares for children aged 0-19 years with diabetes. The clinic population sits between 1300-1500 patients with over 95\% having type 1 diabetes. Two to three patients are newly diagnosed per week. Various staff to patient ratios have been previously published (7), but in toto the patients are seen by 5 consultant paediatric endocrinologists and 3 fellows in training. There is a parallel allied health led outpatient clinic that sees approximately 10 patients per week. At diagnosis patients are randomly allocated to the clinician with the next available clinic appointment and further appointments thereafter booked with the same clinician. All clinicians see patients of all ages and there are no systematic biases in referral patterns. Similarly the clinician group interacts with the allied health group en masse with no specific allied health team member associated with a specific clinician. Continuity of care is emphasized so patients generally see the same clinician continuously throughout the duration of their care at $\mathrm{RCH}$. In the $\mathrm{RCH}$ clinic there are a variety of insulin regimens used from twice daily injections to insulin pump therapy. The frequency of the various regimens has been previously described (8).

Patients and clinical data

Patient information was collected prospectively over two 3 month periods between 1/2/16 to 30/4/16 (T1) and 1/8/16 to $31 / 10 / 16$ (T2) that coincided with autumn and spring. Patient data was included only if: patients had antibody positive, unequivocal type 1 diabetes; the duration of diabetes was greater than 1 year; each individual patient had seen the same consultant on at least 2 consecutive occasions prior to 
each data collection period; and there was no co-existing significant and unrelated disease state. Clinical data that was recorded from the patient record included: patient sex, age and duration of type 1 diabetes; insulin regimen; body mass index (BMI); insulin dose per day (units/kg/day); and episodes of severe hypoglycaemia. BMI Z scores were calculated using published standards (9).

\section{Clinician data}

Clinicians were de-identified and ascribed anonymous labels (Dr A, B C etc). Clinicians completed two questionnaires, the first assessing their attitude towards diabetes and diabetes care, the second a brief personality questionnaire. To assess attitudes towards diabetes care, we asked treating clinicians what they consider to the goals for blood glucose levels and target HbA1C by three age groups, 0-5 yrs, 6-11 yrs and 12-18 yrs. These items have been used previously in an international study of centre differences, and be shown to partially predict the outcomes of diabetes care centres. In addition, individuals completed selected relevant items from the Diabetes Attitude Scale (10), to the clinicians' views about the need for controlling the condition, its psychosocial impact and the degree of autonomy given to children, adolescents and families' decision making. To assess personality, individuals completed the Big Five Inventory 44 (11). This a 44-item questionnaire that assesses the Big Five personality dimensions of agreeableness, conscientiousness, extroversion, emotional stability, and openness to experience. Each item provides a self-descriptive statement, "I see myself as someone who .. ."(is talkative; is a reliable worker; is sometimes shy; is inventive; can be tense), and 
participants rate the extent to which they agree or disagree with the statement on a 5-point scale ranging from 1 (disagree strongly) to 5 (agree strongly) (11).

Statistical analysis

After clinical and questionnaire data were aligned, all clinicians were de-identified prior to analysis. After clinical and questionnaire data were aligned, all clinicians were de-identified prior to analysis. All data were analyses using SPSS V 24. Initial differences between clinicians was tested using analysis of variance for continuous variables, and chi-square for categorical variables. Post Hoc analyses was undertaking using Bonferroni corrections. Once differences between clinicians were established with simple comparisons, all subsequence analysis, with the primary clinical outcome measure as $\mathrm{HbA} 1 \mathrm{C}$, controlled patient sex, age and duration of diabetes, insulin regimen, insulin dose and body mass index and frequency of severe hypoglycaemia, using analysis of co-variance. To determine relative contribution of each variable to the prediction of $\mathrm{HbA1c}$, multiple linear regression was used, with variables entered in pre-planned steps to test the mediating and contributing effects of variables.

This study had approval from the Royal Children's Hospital and Murdoch Children's Research Institute Human Research Ethics Committee. 


\section{Results}

The 8 clinicians saw a total of 464 patients during the first time period, and 603 in the second time period, the characteristics of the children are summarized in Table 1. No children changed clinician during the two time intervals. There was no significant difference in $\mathrm{HbA1C}$ per clinician between the first and second time periods $(\mathrm{F}=3.02$, $\mathrm{df}=1, \mathrm{p}>.05)$ and during both time periods there was a variance (lowest to highest) in mean $\mathrm{HbA} 1 \mathrm{C}$ per clinician of $0.7 \%$. There was a slight increase in reported severe hypoglycaemia during the second time period $(\mathrm{F}=4.62 ; \mathrm{df}=1 ; \mathrm{p}=.032)$. There were small but significant differences between clinicians for age at diagnosis $(\mathrm{F}=3.06 ; \mathrm{df}=7 ; \mathrm{p}<.001)$, duration of diabetes $(F=3.81 ; p<.001)$, age $(F=2.69 ; \mathrm{df}=7 ; \mathrm{p}=.009)$, gender $(C \mathrm{2}=51.78 ; \mathrm{df}=7$; $\mathrm{p}<.001)$, treatment type $(\mathrm{F}=57.9 ; \mathrm{df}=28 ; \mathrm{p}=.001)$ and BMI SD score $(\mathrm{F}=6.72 ; \mathrm{df}=7 ; \mathrm{p}=.006)$. Younger individuals $(\mathrm{r}=.12, \mathrm{p}>.001)$ with shorter duration of diabetes $(\mathrm{r}=.11, \mathrm{p}<.001)$ with lower BMI $((\mathrm{r}=0.14, \mathrm{p}<.001)$ and who are on insulin infusion pumps $(\mathrm{F}=41.43, \mathrm{df}=4 ; \mathrm{p}<.001)$ had lower $\mathrm{HbA1C}$, so analysis of differences between doctors controlled for these variables.

There was a significant difference between clinicians for their patients' mean $\mathrm{HbA} 1 \mathrm{C}(\mathrm{F}=7.50 ; \mathrm{df}=$ $7 ; \mathrm{p}<.001$ ), this result was the same for both time periods, so we report all analysis for the whole sample. In comparison to the overall mean $\mathrm{HbA} 1 \mathrm{C}$ of the sample, Dr B's patients have significantly lower HbA1C than the overall group mean value (mean difference $-0.43 ; \mathrm{p}<.001$ ), Dr C's patients have a higher HbA1c (mean difference $0.34, \mathrm{p}=.006)$ and Dr H's patients have higher HbA1c (mean 
difference $=.27, \mathrm{p}<.001$ ), after controlling for age, duration, BMI, and treatment type. There was no association between the number of patients seen by each clinician and mean $\mathrm{HbA1C}$.

Table 2, provides a summary of clinicians' responses to the different attitude items and questions about treatment targets for HbA1c. All clinicians provided the same targets for blood glucose levels, $4.0-$ $8.0 \mathrm{mmol} / 1$, except Dr C who reported treatment target as 4.0 to $7.0 \mathrm{mmol} / 1$. Dr $\mathrm{C}$ who had this lower blood glucose target also had the lowest treatment target for $\mathrm{HbA1C}$ and was also the only clinician who gave different $\mathrm{HbA} 1 \mathrm{C}$ ranges for different age ranges. Given all other clinicians have given the same target $\mathrm{HbA1C}$ for each age group, we have only used the one item, for further analysis.

The 8 clinicians gave three different answers for target HbA1C. Three clinicians stated a target $\mathrm{HbA} 1 \mathrm{C}$ of $7.5 \%$ for all age groups, four clinicians stated a target $\mathrm{HbA} 1 \mathrm{C}$ of less than $7.5 \%$ for all age groups, whilst one clinician gave a target of 7.0-7.5\% for under 5 year olds and a target of $7.0 \%$ for the other two age groups. Analysis of variance indicated there was a significant association between clinician targets and their patients' $\operatorname{HbA1C}(\mathrm{F}=17.54 ; \mathrm{df}=2 ; \mathrm{p}<.001)$. This analysis indicated that clinicians who did not imply a lower limit to HbA1C target (ie said the target was less than 7.5\%) had patients with lower $\mathrm{HbA1C}($ mean $=7.9)$ than the clinician who whose target was $7.0-7.5 \%($ mean $=$ $8.4 ; \mathrm{p}<001)$ and those who reported a precise target of $7.5 \%($ mean $=8.2 ; \mathrm{p}<.001)$. 
The items focused on the emotional impact of diabetes were summed to create a total score. One clinician strongly agreed with all items that indicated a substantial emotional impact, 2 clinicians strongly agreed with 2 out of the 3 items, with the remaining clinicians having mixed responses across the items. Analysis of variance, controlling age, gender, treatment types, duration and BMI, indicated a significant association between clinician agreement of the emotional impact of diabetes $(\mathrm{F}=8.00 ; \mathrm{df}=$ 3; $\mathrm{p}<.001)$. Planned contrasts, indicated that clinicians who strongly agreed to all three items indicating a strong emotional impact of diabetes had higher mean patient $\mathrm{HbA1C}($ mean $=8.3)$ than clinicians who did not strongly agree to all three items (lowest agreement mean $\mathrm{Hb} 1 \mathrm{C}=7.9 ; \mathrm{p}=.035$ : $2^{\text {nd }}$ lowest agreement mean $\mathrm{HbA} 1 \mathrm{C}=8.1 \% ; \mathrm{p}=.017: 2^{\text {nd }}$ highest agreement mean $\mathrm{HbA} 1 \mathrm{C}=7.9 ; \mathrm{p}$ $<.001$ ). The three items relating to tight control of blood glucose were combined, (reverse scoring appropriate items). Whilst there was a significant association between clinician responses $(\mathrm{F}=10.58$; df $=4 ; 0<.001$ ), there was no clear discernable pattern in the results, and so no further analysis was undertaken. Combining the autonomy items into scale yielded 7 different total scores, so no further analysis was done on the scale. Although clinician responses to each of the items in the autonomy scale showed significant associations with patients' HbA1C, examinations of means showed no consistent pattern.

For personality measures, ANOVA analysis was used to explore relationships between clinicians' selfdescribed personality and their patients' HbA1C levels. As no two clinicians scored the same on a personality scale, these results would be confounded, and would therefore all show a significant effect. 
Therefore, we only accepted personality dimensions that showed a linear association, using planned contrasts, between personality scale scores and HbA1C. Using this criteria, only 'agreeableness' showed a linear association with $\mathrm{HbA1C}$, see Figure 1 (ie clinicians who describe themselves as more agreeable, had patients with higher HbA1C levels [Linear $\mathrm{F}=24.18$, df $=1, \mathrm{p}<.001]$ ). No other personality measures showed a linear or other polynominal relationship with $\mathrm{HbA} 1 \mathrm{C}$.

Therefore, to determine to what extent clinicians' personality, targets and assessment of the emotional impact was related to the outcomes of care a regression analysis was undertaken. With patient $\mathrm{HbA} 1 \mathrm{C}$ as the dependent variable, patient characteristics (age, duration, gender, BMI) and treatment type were entered. On step 2, using stepwise entry, clinician self-reported 'agreeableness', clinician report of patient emotional impact and target $\mathrm{HbA} 1 \mathrm{C}$ were entered as predictors. This analysis indicated that patient characteristics and treatment type accounted for 3\% (Adjusted R Square $=0.027$ ) of the variance in HbA1C levels. Thereafter, clinician target and clinician agreeableness but not emotional impact, were significant predictors of $\mathrm{HbA1C}$, doubling the amount of variance explained (Adjusted R Square $=.062$ ). Finally, adding treatment target and agreeableness as co-variates to the analysis of variance for the effect of Doctor on patient $\mathrm{HbA1C}$, drastically reduced the association between Doctor and $\operatorname{HbA1C}(\mathrm{F}=2.16 ; \mathrm{df}=5 ; \mathrm{p}=.056)$.

\section{Discussion}


In this study we have shown that in a large single centre paediatric diabetes service with one allied health care team, frequent weekly team meetings and a consistent model of care, individual specialist clinician mean $\mathrm{HbA} 1 \mathrm{C}$ outcomes values vary by $0.7 \%$ from lowest to highest values. This variance occurred in a single government-funded tertiary health care setting that provides clinical care for all strata of society within a large multicultural metropolitan context. This variance occurred despite there only being very minor differences between clinicians in their patient characteristics, espoused clinical targets or rates of use of various treatment regimens. After a comprehensive assessment that allowed for these minor differences and further included personality type, diabetes attitudes and clinical practice intent, the only measurable differences associated with lower mean $\mathrm{HbA} 1 \mathrm{C}$ were clinicians who had no lower limit in target $\mathrm{HbA} 1 \mathrm{C}$ and were self-reportedly 'less agreeable'. In other words those clinicians who were more demanding and dogmatic appeared to have better outcomes. The impact of these attitudinal traits were equivalent to the combined effects of patient characteristics and treatment type.

The clinical outcomes of the RCH diabetes clinic are similar for that of the rest of Australia and most developed diabetes care settings $(8,12-17)$. Thus it is likely that the $\mathrm{RCH}$ experience is generaliseable and similar findings will be found in other large paediatric centres. The strengths of this study are that the RCH diabetes clinic is large enough for this study to be undertaken at a single centre, thus controlling for allied health team variables and centre-specific clinical care practices. The size of the $\mathrm{RCH}$ clinic also allowed for selection of patients who were beyond remission phase and who had continuous care with each clinician. As always may occur in studies such as these, there is the potential 
for the introduction of bias by patient selection. Though not impossible, this is unlikely to have occurred in this instance for two reasons. Firstly patients are allocated to physicians in a sequential basis as they are diagnosed with no preferences or systematic selection bias. Secondly the RCH clinic has only 0.14 full time equivalent medical staff per 100 patients (7). The average number of clinic visits per patient is limited to only 2.7 per year (18). Whilst this restricted access is clearly suboptimal according to international guidelines (19), in the context of this study it is problematic for patients to change clinicians and this is consequently an infrequent occurrence. No child studied changed clinician during the two time periods. Thus on the whole, patients are randomly allocated to physicians and for the most part these relationships remain fairly constant. The finding that there was a clinician effect with just 2.7 visits per year further highlights the importance of clinician characteristics.

Therapist effects have been well described in the psychotherapeutic literature- with dyadic terms such as empathy, transference/counter-transference and therapeutic alliance being commonplace (3). These terms acknowledge the processes whereby the therapist and patient engage with each other to achieve a common goal. They recognize that an effective clinical relationship is not simply a didactic transfer of information, rather it encompasses a dynamic undertaking of engagement, reflection and negotiation. All of these processes can be profoundly affected by the attitudes and heuristics of the therapist (4). Clinical medical encounters are not immune from these influences. In particular, the comparison between psychotherapeutic endeavors and those of paediatric diabetes management is apt- paediatric diabetes being in essence a form of behavior management in a patient group who all-too-frequently 
have associated mental health burdens $(20,21)$. Notwithstanding the notional desirability of empathic and engaged clinicians in diabetes, the exact characteristics of effective clinicians remain elusive. In fact the non-transferability of individual therapist effects have been identified as one of the major generaliseability limitations of some psycho-social interventions in paediatric diabetes $(22,23)$. This has led to the search for generic, transferable therapeutic approaches such as motivational interviewing. Unfortunately the benefits of a systematic therapeutic approach have not thus far been demonstrated (24, 25), perhaps implying that 'attitudes' are more important than 'approaches'. Attitudes and expectations of the therapist can also have profound impacts upon how patients and their families receive and process information. As always clear communication is determinative of outcome. In the context of diabetes, the best clinical outcomes appear to occur when there is a confluence of agreed goals (26) within clinical teams, between clinicians and families and within families (27).

The experienced clinician will readily recognize the dilemma that the findings of this study pose. The data from this study indicate that clinical dogmatism around metabolic targets is a key determinant of clinical outcome. Such dogmatism may be in tension with clinical relativism that attempts to equally weight other patient outcomes such as quality of life, patient autonomy and family function. For example an insistence upon achieving metabolic targets and families taking responsibility for decision making may create patient stress, feelings of being judged and unmask latent family dysfunction. In a target-orientated approach, if clinical outcomes are not achieved then consequences will ensue. These might entail a change of insulin regimen, increased supervision by parents or sometimes intervention 
from social services, all of which might create pressures for patients and families. Whilst group data shows an inverse relationship between $\mathrm{HbA} 1 \mathrm{C}$ and quality of life in children and adolescents (28-30) this may not be the case in individual patients in whom the negative impact of an increased burden of care can outweigh any perceived sense of current or future physical well-being. How then to resolve this tension? Whilst there is little empiric evidence, one of the benefits of team-based care might be that it allows one member to be dogmatic about one outcome (ie the clinician and metabolic control) whereas other team members can simultaneously focus upon other issues such as family function, mental health etc. The key to this though is perhaps to have an agreed hierarchy of outcomes within teams whereby one outcome (eg metabolic control) is pre-eminent and the reference point for other secondary outcomes.

Ultimately all decisions on a day to day basis are either made by care-givers or older patients themselves. Practices of shared decision making and increasing patient autonomy are thus advocated (31). An unequivocal approach to clinical outcome priorities by clinicians may also be in tension with these notions. We were unable to demonstrate any association between the amount of autonomy clinicians expected from families and clinical outcome, which perhaps challenges this model in a paediatric context. In reality though, a mixed approach of being "dogmatic about outcome and flexible in approach" (6), that simultaneously accommodates both strong guidance and patient preference, has been shown to be effective in paediatric diabetes management. 
What is the significance of a difference of $0.7 \%$ in mean $\mathrm{HbA} 1 \mathrm{C}$ within one clinic? Perspectives can be gained from the literature. Previous audit-style studies that have addressed variance in mean $\mathrm{HbA1C}$ outcome have focused upon centres within registries. Studies from the Hvidore group showed variation in clinic mean $\mathrm{HbA} 1 \mathrm{C}$ from $7.3 \%$ to $8.9 \%$ (13). This variance has been shown to be relatively immutable over time despite reflection and marked changes in clinical practice, leading to the summation "It's not what you do, it's how you do it" (6). Subsequent registry studies of the DPV and NPDA have shown clinic variance in mean HbA1C of $1.1 \%$ (32) and $2.0 \%$ (17) respectively. It is notable that our within clinic variance in mean $\mathrm{HbA} 1 \mathrm{C}$ is almost double that between the highest and lowest values for clinics in the rest of Australia (7.9-8.3\%) (8). The literature can also provide comparisons in terms of clinical practices and outcomes. The quantum of variance in mean $\mathrm{HbA} 1 \mathrm{C}$ seen in this study attributable to clinician attitude is similar to that seen when parents and patients agree about responsibilities of care (27). It is also similar in scale to those seen after increasing the frequency of blood glucose measurement from 2 to 5 per day (33), use of continuous glucose monitoring greater than $85 \%$ of the time (34) and the use of insulin pump therapy (35). If a within clinic range of mean $\mathrm{HbA} 1 \mathrm{C}$ is $0.7 \%$ then this speaks to what might be considered a meaningful threshold of difference between centres or change due to a clinical intervention. A delta $\mathrm{HbA} 1 \mathrm{C}$ of less than $0.7 \%$ might be considered within only equivalent to within clinic variance and not compelling evidence of real change from baseline. Interestingly the delta figure of $0.7 \%$ is slightly greater than that which health economists judge as a meaningful HbA1C delta in cost effective terms for clinical trials $(0.5 \%)(36$, 37). 
This study has shown that individual clinician attitudes can have significant impacts upon metabolic outcomes in children and adolescents with type 1 diabetes. Within this dataset, the effect of clinician personality and espoused $\mathrm{HbA} 1 \mathrm{C}$ targets on $\mathrm{HbAl} \mathrm{c}$ were equivalent to the combined effect of patient characteristics and treatment type. When compared to other studies, the impact of clinician attitude reported here is compares to the impacts of effective family functioning, adherence with tasks of basic diabetes care or adoption of diabetes technologies. It is also equivalent to the differences in outcomes seen between centres in many diabetes registries. A 'less agreeable', more dogmatic clinical approach was found to be associated with improved metabolic outcomes. This can be challenging in the context of holistic care when other health and psychological needs may compete for priority. Notwithstanding this, our data indicate that these attitudes should be central philosophy for teams engaged in paediatric diabetes care.

Acknowledgements:

We would like to acknowledge our colleagues who trusted us to undertake this work in a collegial, respectful and anonymized manner. 


\section{References}

1) Cerreto MC, Travis LB. Implications of psychological and family factors in the treatment of diabetes. Pediatr Clin North Am 1984; 31:689-710.

2) Walwyn R, Roberts C. Therapist variation within randomised trials of psychotherapy: implications for precision, internal and external validity. Stat Methods Med Res 2010; 19:291-315.

3) Murphy R, Hutton P. Practitioner Review: Therapist variability, patient-reported therapeutic alliance, and clinical outcomes in adolescents undergoing mental health treatment - a systematic review and meta-analysis. J Child Psychol Psychiatry 2017 [Epub ahead of print]

4) Kahneman D. 'Thinking, fast and slow'. Farrar, Straus and Giroux New York, 2011.

5) Murphy HR, Rayman G, Skinner TC. Psycho-educational interventions for children and young people with Type 1 diabetes. Diabet Med 2006; 23:935-43.

6) Cameron FJ, de Beaufort C, Aanstoot HJ, Hoey H, Lange K, Castano L, Mortensen HB; Hvidoere International Study Group. Lessons from the Hvidoere International Study Group on childhood diabetes: be dogmatic about outcome and flexible in approach. Pediatr Diabetes 2013; 14:473-80.

This article is protected by copyright. All rights reserved. 
7) Cameron F, Cotterill A, Couper J, Craig M, Davis E, Donaghue K, Jones T, King B, Sheil B. Short report: Care for children and adolescents with diabetes in Australia and New Zealand: have we achieved the defined goals? J Paediatr Child Health 2013; 49(4):E258-62.

8) Phelan H, Clapin H, Bruns L, Cameron FJ, Cotterill AM, Couper JJ, Davis EA, Donaghue KC, Jefferies CA, King BR, Sinnott RO, Tham EB, Wales JK, Jones TW, Craig ME. The Australasian Diabetes Data Network: first national audit of children and adolescents with type 1 diabetes. Med J Aust 2017; 206:121-125.

9) WHO Multicentre Growth Reference Study Group. WHO Child Growth Standards based on length/height, weight and age. Acta Paediatr Supp. 2006; 450:76-85.

10) Anderson Rm, Fitzgerald JT, Funnell MM Gruppen LD. The Third Version of the Diabetes Attitude Scale. Diabetes Care 1998; 21: 1403-1407.

11) John OP, Donahue EM, Kentle RL. (1991). The Big Five Inventory--Versions 4a and 54. Berkeley, CA: University of California,Berkeley, Institute of Personality and Social Research. 
12) de Beaufort CE, Swift PG, Skinner CT, Aanstoot HJ, Aman J, Cameron F, Martul P, Chiarelli F, Daneman D, Danne T, Dorchy H, Hoey H, Kaprio EA, Kaufman F, Kocova M, Mortensen HB, Njølstad PR, Phillip M, Robertson KJ, Schoenle EJ, Urakami T, Vanelli M; Hvidoere Study Group on Childhood Diabetes 2005. Continuing stability of center differences in pediatric diabetes care: do advances in diabetes treatment improve outcome? The Hvidoere Study Group on Childhood Diabetes. Diabetes Care. 2007; 30:2245-50.

13) de Beaufort CE, Lange K, Swift PG, Aman J, Cameron F, Castano L, Dorchy H, Fisher LK, Hoey H, Kaprio E, Kocova M, Neu A, Njolstad PR, Phillip M, Schoenle E, Robert JJ, Urukami T, Vanelli M, Danne T, Barrett T, Chiarelli F, Aanstoot HJ, Mortensen HB; Hvidoere Study Group. Metabolic outcomes in young children with type 1 diabetes differ between treatment centers: the Hvidoere Study in Young Children 2009. Pediatr Diabetes 2013; 14:422-8.

14) Hofer SE, Raile K, Fröhlich-Reiterer E, Kapellen T, Dost A, Rosenbauer J, Grulich-Henn J, Holl RW; Austrian/German Diabetes Patienten Verlaufsdokumentation DPV Initiative; German Competence Network for Diabetes Mellitus.Tracking of metabolic control from childhood to young adulthood in type 1 diabetes. J Pediatr 2014; 165:956-61.e1-2.

This article is protected by copyright. All rights reserved. 
15) Marcovecchio ML, Woodside J, Jones T, Daneman D, Neil A, Prevost T, Dalton RN, Deanfield J, Dunger DB; AdDIT Investigators. Adolescent Type 1 Diabetes Cardio-Renal Intervention Trial (AdDIT): urinary screening and baseline biochemical and cardiovascular assessments. Diabetes Care 2014; 37:805-13.

16) Miller KM, Foster NC, Beck RW, Bergenstal RM, DuBose SN, DiMeglio LA, Maahs DM, Tamborlane WV T1D Exchange Clinic Network. Current state of type 1 diabetes treatment in the U.S.: updated data from the T1D Exchange clinic registry. Diabetes Care 2015; 38:971-8.

17) National Paediatric Diabetes Audit 2016. http://www.rcpch.ac.uk/national-paediatric-diabetesaudit-npda.

18) Simm PJ, Wong N, Fraser L, Kearney J, Fenton J, Jachno K, Cameron FJ. Geography does not limit optimal diabetes care: use of a tertiary centre model of care in an outreach service for type 1 diabetes mellitus. J Paediatr Child Health 2014; 50:471-5.

19) Rewers MJ, Pillay K, de Beaufort C, Craig ME, Hanas R, Acerini CL, Maahs DM; International Society for Pediatric and Adolescent Diabetes. ISPAD Clinical Practice Consensus Guidelines 2014. Assessment and monitoring of glycemic control in children and adolescents with diabetes. Pediatr Diabetes 2014; 15 Suppl 20:102-14.

This article is protected by copyright. All rights reserved. 
20) Cameron FJ, Northam EA, Ambler GR, Daneman D. Routine psychological screening in youth with type 1 diabetes and their parents: a notion whose time has come? Diabetes Care 2007; 30:2716-24.

21) Young-Hyman D, de Groot M, Hill-Briggs F, Gonzalez JS, Hood K, Peyrot M. Psychosocial Care for People With Diabetes: A Position Statement of the American Diabetes Association. Diabetes Care 2016; 39:2126-2140.

22) Northam EA, Todd S, Cameron FJ. Interventions to promote optimal health outcomes in children with Type 1 diabetes--are they effective? Diabet Med 2006; 23:113-21.

23) Murphy HR, Rayman G, Skinner TC. Psycho-educational interventions for children and young people with Type 1 diabetes. Diabet Med 2006; 23:935-43.

24) Wang YC, Stewart SM, Mackenzie M, Nakonezny PA, Edwards D, White PC. A randomized controlled trial comparing motivational interviewing in education to structured diabetes education in teens with type 1 diabetes. Diabetes Care 2010; 33:1741-3.

This article is protected by copyright. All rights reserved. 
25) Robling M, McNamara R, Bennert K, Butler CC, Channon S, Cohen D, Crowne E, Hambly H, Hawthorne K, Hood K, Longo M, Lowes L, Pickles T, Playle R, Rollnick S, Thomas-Jones E, Gregory JW. The effect of the Talking Diabetes consulting skills intervention on glycaemic control and quality of life in children with type 1 diabetes: cluster randomised controlled trial (DEPICTED study). BMJ 2012; 344:e2359.

26) Swift PG, Skinner TC, de Beaufort CE, Cameron FJ, Aman J, Aanstoot HJ, Castaño L, Chiarelli F, Daneman D, Danne T, Dorchy H, Hoey H, Kaprio EA, Kaufman F, Kocova M, Mortensen HB, Njølstad PR, Phillip M, Robertson KJ, Schoenle EJ, Urakami T, Vanelli M, Ackermann RW, Skovlund SE; Hvidoere Study Group on Childhood Diabetes. Target setting in intensive insulin management is associated with metabolic control: the Hvidoere childhood diabetes study group centre differences study 2005. Pediatr Diabetes 2010; 11. 271-8.

27) Cameron FJ, Skinner TC, de Beaufort CE, Hoey H, Swift PG, Aanstoot H, Aman J, Martul P, Chiarelli F, Daneman D, Danne T, Dorchy H, Kaprio EA, Kaufman F, Kocova M, Mortensen HB, Njølstad PR, Phillip M, Robertson KJ, Schoenle EJ, Urakami T, Vanelli M, Ackermann RW, Skovlund SE; Hvidoere Study Group on Childhood Diabetes. Are family factors universally related to metabolic outcomes in adolescents with Type 1 diabetes? Diabet Med 2008; 25:463-8.

This article is protected by copyright. All rights reserved. 
28) Hoey H; Hvidoere Study Group on Childhood Diabetes. Psychosocial factors are associated with metabolic control in adolescents: research from the Hvidoere Study Group on Childhood Diabetes. Pediatr Diabetes 2009; 10 Suppl 13:9-14.

29) de Wit M, Winterdijk P, Aanstoot HJ, Anderson B, Danne T, Deeb L, Lange K, Nielsen AØ, Skovlund S, Peyrot M, Snoek F; DAWN Youth Advisory Board. Assessing diabetes-related quality of life of youth with type 1 diabetes in routine clinical care: the MIND Youth Questionnaire (MY-Q). Pediatr Diabetes 2012; 13:638-46.

30) Anderson BJ, Laffel LM, Domenger C, Danne T, Phillip M, Mazza C, Hanas R, Waldron S, Beck RW, Calvi-Gries F, Mathieu C. Factors Associated With Diabetes-Specific Health-Related Quality of Life in Youth With Type 1 Diabetes: The Global TEENs Study. Diabetes Care 2017; 40:1002-1009.

31) Sandman L, Munthe C.Shared decision-making and patient autonomy. Theor Med Bioeth 2009; 30:289-310.

32) Bohn B, Rosenbauer J, Icks A, Vogel C, Beyer P, Rütschle H, Hermann U, Holterhus PM, Wagner V, von Sengbusch S, Fink K, Holl RW; DPV initiative. Regional Disparities in Diabetes Care for 
Pediatric Patients with Type 1 Diabetes. A Cross-sectional DPV Multicenter Analysis of 24,928 German Children and Adolescents. Exp Clin Endocrinol Diabetes 2016; 124:111-9.

33) Petry NM, Cengiz E, Wagner JA, Weyman K, Tichy E, Tamborlane WV. Testing for rewards: a pilot study to improve type 1 diabetes management in adolescents. Diabetes Care 2015; 38:1952-4.

34) Juvenile Diabetes Research Foundation Continuous Glucose Monitoring Study Group, Beck RW, Buckingham B, Miller K, Wolpert H, Xing D, Block JM, Chase HP, Hirsch I, Kollman C, Laffel L, Lawrence JM, Milaszewski K, Ruedy KJ, Tamborlane WV. Factors predictive of use and of benefit from continuous glucose monitoring in type 1 diabetes. Diabetes Care 2009; 32:1947-53.

35) Bergenstal RM, Tamborlane WV, Ahmann A, Buse JB, Dailey G, Davis SN, Joyce C, Peoples T, Perkins BA, Welsh JB, Willi SM, Wood MA; STAR 3 Study Group. Effectiveness of sensoraugmented insulin-pump therapy in type 1 diabetes. N Engl J Med 2010; 363:311-20.

36) Cummins E, Royle P, Snaith A, Greene A, Robertson L, McIntyre L, Waugh N. Clinical effectiveness and cost-effectiveness of continuous subcutaneous insulin infusion for diabetes: systematic review and economic evaluation. Health Technol Assess 2010;14:iii-iv, xi-xvi, 1-181.

This article is protected by copyright. All rights reserved. 
37) Clar C, Barnard K, Cummins E, Royle P, Waugh N; Aberdeen Health Technology Assessment Group. Self-monitoring of blood glucose in type 2 diabetes: systematic review. Health Technol Assess $2010 ; 14: 1-140$. 
Table 1: Characteristics of clinic doctors and patients seen at the two time intervals.

\begin{tabular}{|c|c|c|c|c|c|c|c|c|c|c|c|c|c|c|c|c|c|c|}
\hline \multirow{2}{*}{$\begin{array}{l}\text { Patients } \\
\text { characteristics }\end{array}$} & \multicolumn{2}{|c|}{$\begin{array}{l}\text { Total } \\
\text { clinic }\end{array}$} & \multicolumn{2}{|c|}{ Dr A } & \multicolumn{2}{|c|}{ Dr B } & \multicolumn{2}{|c|}{ Dr C } & \multicolumn{2}{|c|}{ Dr D } & \multicolumn{2}{|c|}{ Dr E } & \multicolumn{2}{|c|}{ Dr F } & \multicolumn{2}{|c|}{ Dr G } & \multicolumn{2}{|c|}{ Dr H } \\
\hline & $\mathrm{T} 1$ & $\mathrm{~T} 2$ & T1 & $\mathrm{T} 2$ & $\mathrm{~T} 1$ & $\mathrm{~T} 2$ & $\mathrm{~T} 1$ & $\mathrm{~T} 2$ & T1 & $\mathrm{T} 2$ & $\mathrm{~T} 1$ & $\mathrm{~T} 2$ & $\mathrm{~T} 1$ & $\mathrm{~T} 2$ & T1 & $\mathrm{T} 2$ & $\mathrm{~T} 1$ & $\mathrm{~T} 2$ \\
\hline No of pts seen & 464 & 602 & 70 & 92 & 73 & 115 & 12 & 65 & 36 & 42 & 13 & 20 & 47 & 40 & 103 & 111 & 110 & 117 \\
\hline Percent male & $50 \%$ & $52 \%$ & $40 \%$ & $38 \%$ & $55 \%$ & $52 \%$ & $100 \%$ & $71 \%$ & $47 \%$ & $69 \%$ & $31 \%$ & $30 \%$ & $66 \%$ & $65 \%$ & $41 \%$ & $42 \%$ & $55 \%$ & $56 \%$ \\
\hline $\begin{array}{l}\text { Mean (SD)duration of } \\
\text { diabetes }\end{array}$ & $\begin{array}{l}6.1 \\
(3.5)\end{array}$ & $\begin{array}{l}6.1 \\
(3.7)\end{array}$ & $\begin{array}{l}5.5 \\
(3.5)\end{array}$ & $\begin{array}{l}5.8 \\
(3.4)\end{array}$ & $\begin{array}{l}7.1 \\
(3.9)\end{array}$ & $\begin{array}{l}7.1 \\
(3.9)\end{array}$ & $\begin{array}{l}6.0 \\
(3.5)\end{array}$ & $\begin{array}{l}6.1 \\
(4.2)\end{array}$ & $\begin{array}{l}5.1 \\
(3.3)\end{array}$ & $\begin{array}{l}5.5 \\
(3.0)\end{array}$ & $\begin{array}{l}5.8 \\
(2.5)\end{array}$ & $\begin{array}{l}5.8 \\
(2.7)\end{array}$ & $\begin{array}{l}5.4 \\
(3.5)\end{array}$ & $\begin{array}{l}5.7 \\
(3.6)\end{array}$ & $\begin{array}{l}6.5 \\
(3.5)\end{array}$ & $\begin{array}{l}6.1 \\
(3.8)\end{array}$ & $\begin{array}{l}6.0 \\
(3.4)\end{array}$ & $\begin{array}{l}5.9 \\
(3.5)\end{array}$ \\
\hline Mean (SD) age & $\begin{array}{l}13.0 \\
(3.9)\end{array}$ & $\begin{array}{l}13.3 \\
(3.8)\end{array}$ & $\begin{array}{l}13.2 \\
(3.8)\end{array}$ & $\begin{array}{l}14.0 \\
(3.5)\end{array}$ & $\begin{array}{l}13.5 \\
(3.8)\end{array}$ & $\begin{array}{l}14.2 \\
(3.6)\end{array}$ & $\begin{array}{l}12.6 \\
(4.2)\end{array}$ & $\begin{array}{l}13.0 \\
(3.9)\end{array}$ & $\begin{array}{l}12.5 \\
(4.0)\end{array}$ & $\begin{array}{l}12.7 \\
(3.9)\end{array}$ & $\begin{array}{l}12.4 \\
(4.2)\end{array}$ & $\begin{array}{l}12.3 \\
(4.0)\end{array}$ & $\begin{array}{l}12.4 \\
(4.1)\end{array}$ & $\begin{array}{l}12.3 \\
(3.9)\end{array}$ & $\begin{array}{l}12.7 \\
(4.2)\end{array}$ & $\begin{array}{l}12.8 \\
(4.0)\end{array}$ & $\begin{array}{l}13.4 \\
(3.6)\end{array}$ & $\begin{array}{l}13.2 \\
(3.6)\end{array}$ \\
\hline $\begin{array}{l}\% \text { on BD insulin (free- } \\
\text { mix) }\end{array}$ & $29 \%$ & $31 \%$ & $39 \%$ & $38 \%$ & $37 \%$ & $33 \%$ & $17 \%$ & $39 \%$ & $33 \%$ & $41 \%$ & $39 \%$ & $40 \%$ & $28 \%$ & $28 \%$ & $24 \%$ & $21 \%$ & $23 \%$ & $26 \%$ \\
\hline $\begin{array}{l}\% \text { on MDI } \\
\text { Insulin }\end{array}$ & $31 \%$ & $34 \%$ & $36 \%$ & $34 \%$ & $22 \%$ & $30 \%$ & $33 \%$ & $39 \%$ & $33 \%$ & $33 \%$ & $23 \%$ & $30 \%$ & $34 \%$ & $43 \%$ & $29 \%$ & $30 \%$ & $36 \%$ & $36 \%$ \\
\hline$\%$ on CSII & $34 \%$ & $31 \%$ & $20 \%$ & $19 \%$ & $37 \%$ & $34 \%$ & $42 \%$ & $20 \%$ & $22 \%$ & $21 \%$ & $23 \%$ & $25 \%$ & $30 \%$ & $23 \%$ & $42 \%$ & $45 \%$ & $38 \%$ & $36 \%$ \\
\hline $\begin{array}{l}\% \text { on other insulin } \\
\text { regimen (pre-mix) }\end{array}$ & $6 \%$ & $4 \%$ & $5 \%$ & $9 \%$ & $4 \%$ & $3 \%$ & $8 \%$ & $2 \%$ & $12 \%$ & $5 \%$ & $15 \%$ & $5 \%$ & $8 \%$ & $6 \%$ & $5 \%$ & $4 \%$ & $3 \%$ & $2 \%$ \\
\hline Mean HbA1C (SD) & $\begin{array}{l}8.0 \\
(1.1)\end{array}$ & $\begin{array}{l}8.1 \\
(1.1)\end{array}$ & $\begin{array}{l}7.9 \\
(1.1)\end{array}$ & $\begin{array}{l}8.1 \\
(1.2)\end{array}$ & $\begin{array}{l}7.5 \\
(0.9)\end{array}$ & $\begin{array}{l}7.8 \\
(1.0)\end{array}$ & $\begin{array}{l}8.0 \\
(0.9)\end{array}$ & $\begin{array}{l}8.5 \\
(1.2)\end{array}$ & $\begin{array}{l}7.9 \\
(1.0)\end{array}$ & $\begin{array}{l}8.2 \\
(0.9)\end{array}$ & $\begin{array}{l}7.9 \\
(0.9)\end{array}$ & $\begin{array}{l}8.0 \\
(1.1)\end{array}$ & $\begin{array}{l}8.1 \\
(1.1)\end{array}$ & $\begin{array}{l}8.2 \\
(0.8)\end{array}$ & $\begin{array}{l}8.1 \\
(1.3)\end{array}$ & $\begin{array}{l}7.9 \\
(1.1)\end{array}$ & $\begin{array}{l}8.2 \\
(1.1)\end{array}$ & $\begin{array}{l}8.4 \\
(1.3)\end{array}$ \\
\hline
\end{tabular}

This article is protected by copyright. All rights reserved. 


\begin{tabular}{|l|l|l|l|l|l|l|l|l|l|l|l|l|l|l|l|l|l|l|l|}
\hline $\begin{array}{l}\text { No of episodes severe } \\
\text { hypoglycaemia }\end{array}$ & 1 & 8 & 1 & 3 & 0 & 1 & 0 & 0 & 0 & 0 & 0 & 1 & 0 & 0 & 0 & 3 & 0 & 1 \\
\hline
\end{tabular}

$\mathrm{T} 1=$ time interval 31/1/16 to 31/3/16. T2 = time interval $1 / 8 / 16$ to 31/10/1. BD insulin = insulin given at two time points, free-mixing short and intermediate acting, MDI insulin = 3-4 injections per day, Other insulin regimen = premixed insulin given twice a day or insulin metformin combination. 
This article is protected by copyright. All rights reserved. 
Table 2. Summary of Clinician Responses to Attitudes and Targets Questions

\begin{tabular}{|c|c|c|c|c|c|}
\hline Attitude Items & $\begin{array}{l}\text { Strongly } \\
\text { Disagree }\end{array}$ & Disagree & $\begin{array}{l}\text { Neither } \\
\text { Agree or } \\
\text { Disagree }\end{array}$ & Agree & $\begin{array}{l}\text { Strongly } \\
\text { Agree }\end{array}$ \\
\hline \multicolumn{6}{|c|}{ Emotional Impact } \\
\hline $\begin{array}{l}\text { Diabetes affects almost every part of a } \\
\text { child with diabetes life. }\end{array}$ & 0 & 0 & 0 & 3 & 5 \\
\hline $\begin{array}{l}\text { The emotional effects of diabetes are } \\
\text { pretty small. }\end{array}$ & 7 & 1 & 0 & 0 & 0 \\
\hline $\begin{array}{l}\text { Having diabetes changes a person's } \\
\text { outlook on life. }\end{array}$ & 0 & 0 & 1 & 6 & 1 \\
\hline \multicolumn{6}{|c|}{ Autonomy } \\
\hline $\begin{array}{l}\text { The important decisions regarding daily } \\
\text { diabetes care should be made by the child } \\
\text { with diabetes/parent }\end{array}$ & 0 & 1 & 2 & 2 & 3 \\
\hline $\begin{array}{l}\text { Health care professionals should help } \\
\text { children and parents make informed } \\
\text { choices about their care plans. }\end{array}$ & 0 & 0 & 0 & 1 & 7 \\
\hline $\begin{array}{l}\text { Children and parents with diabetes should } \\
\text { have the final say in setting their blood } \\
\text { glucose goals. }\end{array}$ & 2 & 5 & 0 & 1 & 0 \\
\hline Health care professionals should learn how & 0 & 1 & 0 & 3 & 4 \\
\hline
\end{tabular}

This article is protected by copyright. All rights reserved. 


\begin{tabular}{|l|c|c|c|c|}
\hline $\begin{array}{l}\text { to set goals with patients, not just tell them } \\
\text { what to do. }\end{array}$ & & & & \\
\hline $\begin{array}{l}\text { People with diabetes have the right not to } \\
\text { take good care of their diabetes }\end{array}$ & 2 & 2 & 2 & 2 \\
\hline
\end{tabular}

Importance of Control

\begin{tabular}{|l|c|c|c|c|c|}
\hline $\begin{array}{l}\text { Low blood sugar reactions make tight } \\
\text { control too risky for most children with } \\
\text { diabetes. }\end{array}$ & 6 & 2 & 0 & 0 \\
\hline $\begin{array}{l}\text { Almost everyone with diabetes should do } \\
\text { whatever it takes to keep their blood sugar } \\
\text { close to normal }\end{array}$ & 0 & 0 & 1 & 0 & 7 \\
\hline Tight control is too much work & 3 & 4 & 0 & 1 & 0 \\
\hline \multicolumn{1}{|c|}{ Targets } & 7.0 & $7.0-7.5$ & Less than & 7.5 & \\
\hline Target Hba1c $<5$ years of age & & 1 & 4 & 3 & 3 \\
\hline Target HbA1c 5-10 years of age & 1 & & 4 & 4 & 3 \\
\hline Target HbA1C $>10$ years of age & & & 1 & & \\
\hline
\end{tabular}

This article is protected by copyright. All rights reserved. 
Figure 1. Mean and 95\% Confidence Intervals for HbA1c by Doctors Agreeableness Score.(NB Two out of 8 clinicians scored the same on the Doctor agreeableness core- their data are combined) 


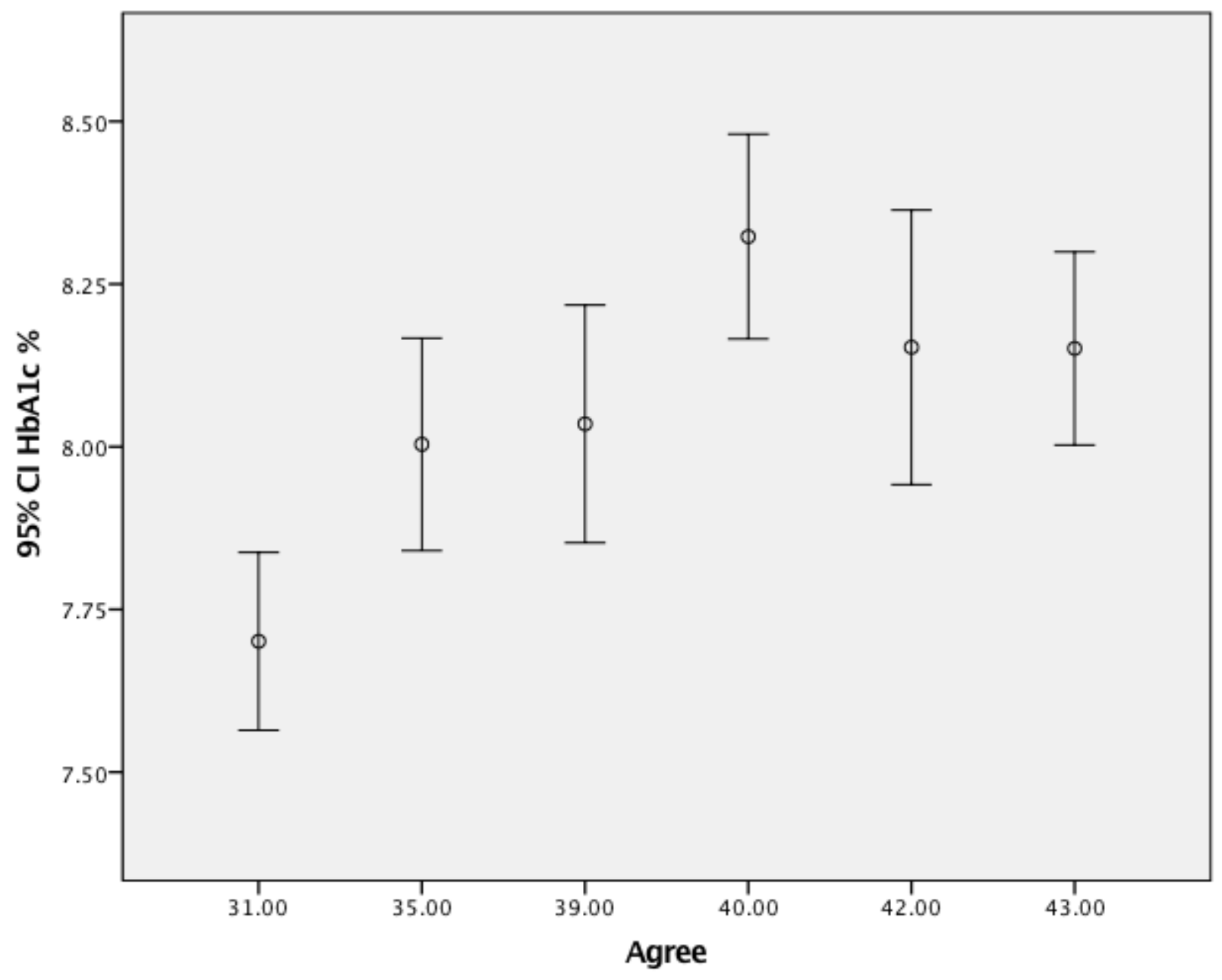

This article is protected by copyright. All rights reserved. 
This article is protected by copyright. All rights reserved. 
This article is protected by copyright. All rights reserved. 


\section{University Library}

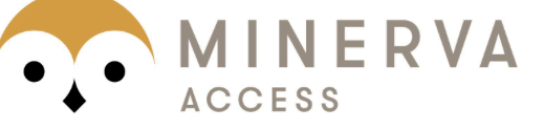

A gateway to Melbourne's research publications

Minerva Access is the Institutional Repository of The University of Melbourne

Author/s:

Cameron, FJ;Russell, E;McCombe, J;O'Connell, MA;Skinner, T

Title:

The clinician factor: Personality characteristics of clinicians and their impact upon clinical outcomes in the management of children and adolescents with type 1 diabetes

Date:

2018-06-01

Citation:

Cameron, F. J., Russell, E., McCombe, J., O'Connell, M. A. \& Skinner, T. (2018). The clinician factor: Personality characteristics of clinicians and their impact upon clinical outcomes in the management of children and adolescents with type 1 diabetes. PEDIATRIC DIABETES, 19 (4), pp.832-839. https://doi.org/10.1111/pedi.12646.

Persistent Link:

http://hdl.handle.net/11343/283774 